\title{
Does right hemisphere superiority sufficiently explain the left visual field advantage in face recognition?
}

\author{
Matthew T. Harrison ${ }^{1} \cdot$ Lars Strother $^{1}$ \\ Published online: 26 November 2019 \\ (C) The Psychonomic Society, Inc. 2019
}

\begin{abstract}
The tendency to perceive the identity of the left half of a centrally viewed face more strongly than that of the right half is associated with visual processing of faces in the right hemisphere (RH). Here we investigate conditions under which this wellknown left visual field (LVF) half-face advantage fails to occur. Our findings challenge the sufficiency of its explanation as a function of RH specialization for face processing coupled with LVF-RH correspondence. In two experiments we show that the LVF half-face advantage occurs for normal faces and chimeric faces composed of different half-face identities. In a third experiment, we show that face inversion disrupts the LVF half-face advantage. In two additional experiments we show that half-faces viewed in isolation or paired with inverted half-faces fail to show the LVF advantage. Consistent with previous explanations of the LVF half-face advantage, our findings suggest that the LVF half-face advantage reflects RH superiority for processing faces and direct transfer of LVF face information to visual cortex in the RH. Critically, however, our findings also suggest the operation of a third factor, which involves the prioritization of face-processing resources to the LVF, but only when two upright face-halves compete for these resources. We therefore conclude that RH superiority alone does not suffice to explain the LVF advantage in face recognition. We also discuss the implications of our findings for specialized visual processing of faces by the right hemisphere, and we distinguish LVF advantages for faces viewed centrally and peripherally in divided field studies.
\end{abstract}

Keywords Face recognition $\cdot$ Hemispheric specialization $\cdot$ Visual field bias $\cdot$ Holistic processing $\cdot$ Visual perception

\section{Introduction}

Humans are experts at recognizing faces. Our ability to recognize faces is strongly associated with neural mechanisms in the right cerebral hemisphere. This association is supported by findings from numerous studies of brain-damaged patients and neuroimaging studies of normal and impaired face recognizers. Directly related to the involvement of the right hemisphere $(\mathrm{RH})$ in face processing, the common finding of a left visual field (LVF) advantage in face recognition has been interpreted as behavioral evidence of RH superiority for face recognition (Brady, Campbell, \& Flaherty, 2005; Burt \& Perrett, 1997; Coolican, Eskes, McMullen, \& Lecky, 2008; Dundas, Plaut, \& Behrmann, 2015; Gilbert \& Bakan, 1973; Heller \& Levy, 1981; Hilliard, 1973; Rizzolatti, Umiltà, \&

Matthew T. Harrison

mt.harrison@gmail.com

1 Department of Psychology, University of Nevada Reno, MS0296, 1664 N. Virginia Street, Reno, NV 89557, USA
Berlucchi, 1971). This interpretation assumes a contralateral correspondence between visual information in the LVF and visual processing by neural mechanisms in the RH, which is consistent with the known neural architecture of the human visual system.

Two different types of LVF advantage are commonly reported, one for centrally viewed faces and another for peripherally viewed faces. For centrally viewed faces, the left half of the face dominates the right half perceptually (Wolff, 1933). A corresponding $L V F$ half-face advantage in face recognition has been shown by measuring the degree to which visual input corresponding to the left half of a centrally viewed face contributes more strongly to face-recognition performance than that corresponding to the right half (Brady et al., 2005; Burt \& Perrett, 1997; Coolican et al., 2008; Gilbert \& Bakan, 1973; Luh, Rueckert, \& Levy, 1991). This type of LVF advantage for centrally viewed faces is associated with right-lateralized face recognition mechanisms (Boremanse, Norcia, \& Rossion, 2013; Yovel, Levy, Grabowecky, \& Paller, 2003; Yovel, Tambini, \& Brandman, 2008). A similar and possibly related LVF advantage in face-recognition performance has been shown using divided visual field experiments in which 
whole faces are viewed in either the left or right peripheral visual field (Dundas, Plaut, \& Behrmann, 2013; Hilliard, 1973; Rizzolatti et al., 1971). For either method, the logic is that stimulus information in each visual field is initially projected to and processed by visual cortex in the contralateral hemisphere (Beaumont, 1983). Differences in facerecognition performance between the two hemifields, either for half-faces or whole faces, therefore arise either prior to or during interhemispheric transfer (Rizzolatti et al., 1971), and thus index LVF/RH superiority for face recognition.

The existence of RH superiority for face recognition implies that neural mechanisms in the RH are better suited to the visual processing of faces than those in the left hemisphere (LH). Some studies have shown RH superiority for processing the low spatial frequency components of faces (Keenan, Whitman, \& Pepe, 1989; Sergent, 1985). Other studies have emphasized RH-LH differences in the type of visual processing underlying face recognition, especially the visual processing of spatial relationships inherent in global visual input especially in the context of "holistic" or "configural" processing (Maurer, Le Grand, \& Mondloch, 2002; Mckone \& Yovel, 2009; Piepers \& Robbins, 2012) - which may be directly related to spatial frequency processing differences between the two hemispheres (Goffaux \& Rossion, 2006; Sergent, 1982b). Specifically, it has been proposed that the RH more strongly underlies visual processing of spatial relationships whereas the LH is more strongly affiliated with featurebased processing (Hillger \& Koenig, 1991; Martinez et al., 1997; Rossion et al., 2000; Van Kleeck, 1989). Whether or not differences in visual processing between the two hemispheres are limited to specialized visual processing of faces (Kanwisher, McDermott, \& Chun, 1997) or apply to other objects of expertise (Gauthier, Tarr, Anderson, Skudlarski, \& Gore, 1999), is a topic of ongoing debate. Regardless, there is considerable consensus that although the right and left hemispheres are both involved in face recognition, their respective contributions to the visual processing of faces may differ.

Despite the plausibility of RH superiority for face processing as an explanation for the LVF half-face advantage, existing findings show that the advantage does not always occur and that RH superiority itself may not suffice to explain the advantage. For instance, the results of experiments by Liu, Hayward, Oxner, and Behrmann (2014) found that LVF and RVF half-faces can be processed equally well for recognition purposes when cued. This means that, under some conditions, the LH can processes RVF half-faces as well as the RH processes LVF half-faces, unless LVF-RH/ RVF-LH logic does not apply. Other results are also consistent with the possibility that RH-LH differences in face processing can be negated under certain conditions (Hillger \& Koenig, 1991; Levine \& Koch-Weser, 1982; Marzi \& Berlucchi, 1977; Sergent, 1984b), but whether or not these findings challenge the sufficiency of RH superiority as an explanation for the
LVF half-face advantage is unclear. In addition to studies showing that the LVF half-face bias does not always occur, other findings complicate RH superiority as it relates to the spatial location of half-face information. For example, normal fixation for centrally viewed faces initially lands to the left of center, placing most of the face in the RVF (Hsiao \& Liu, 2012), thus projecting the majority of the face to the LH rather than to the RH. This suggests that normal viewing of faces does not take advantage of RH superiority according to the strict LVF-RH mapping implied by the logic of the divided field paradigm described earlier. This logic is further challenged by the lack of independence of processing of each half of a face by the contralateral hemisphere (Hole, 1994; Yovel, Paller, \& Levy, 2005). We therefore conducted several experiments with the goal of testing whether or not superior face processing in the RH and a corresponding contralateral visual field bias suffice to explain the LVF half-face advantage.

Of particular interest in our study is to identify face viewing conditions under which the LVF half-face advantage occurs or not, and to compare these conditions to those reported previously for whole faces viewed in the periphery. In Experiments $1 \mathrm{a}$ and $1 \mathrm{~b}$, we show that the LVF half-face advantage occurs for normal centrally viewed faces, and also for chimeric faces comprised of half-faces corresponding to different individuals, which is consistent with previous findings (Brady et al., 2005; Burt \& Perrett, 1997; Coolican et al., 2008; Gilbert \& Bakan, 1973; Luh et al., 1991). Critically, we also show that the degree of LVF half-face advantage for normal faces predicts the effect for chimeric faces, which is crucial for justifying our remaining experiments. In Experiment 2a, we show that face inversion abolishes the LVF half-face advantage, possibly due to the disproportionate disruption of visual processing of spatial relations between the two hemispheres (Freire, Lee, \& Symons, 2000; Sergent, 1984a). In Experiment 2b, we use occlusion to show that the LVF halfface advantage does not occur for upright half-faces viewed in isolation, but that an inversion effect does. Finally, in Experiment 3, we pair upright and inverted half-faces to show that the LVF half-face advantage is not disrupted by inverting the right visual field (RVF) half-face, but that an RVF halfface advantage emerges when the LVF half is inverted. Taken together, our results show that the LVF half-face advantage reflects a left hemisphere deficit in face processing, which occurs when stimulus input to the RH is sufficient for face recognition and negates the need for left hemisphere processing of RVF input. However, when LVF input to the RH is compromised by half-face occlusion or inversion, the left hemisphere performs RVF half-face processing as well as the RH performs LVF half-face processing. We therefore conclude that the RH superiority account of an LVF advantage in face recognition is insufficient to the degree that it posits inherent obligatory visual processing limitations of RVF relative to LVF face stimuli. 


\section{Experiments $1 \mathrm{a}$ and $\mathbf{1 b}$}

The purpose of Experiments 1a and $1 \mathrm{~b}$ was to investigate the LVF half-face advantage in two different identitymatching tasks. Experiment 1a was a partial replication of Gilbert and Bakan (1973). Participants viewed a briefly presented target whole face, and then chose which of two reference chimeric faces was perceived to be more similar, one composed of mirror-reversed copies of the left half of the whole face and the other composed of mirror-reversed copies of the right half of the whole face. The LVF halfface advantage was measured by comparing how often the LVF composite was chosen, relative to the RVF composite. In Experiment 1b, a target chimeric face composed of left and right halves of different faces was briefly presented, and participants chose a match from between two reference chimeric faces, one of which differed from the target face in either the left or right half-face. The halfface in which one of the reference faces differed from the target face was therefore diagnostic for determining which reference face matched the target. The LVF half-face advantage was measured by comparing accuracy for trials in which the diagnostic half-face was in the LVF to trials in which the diagnostic half-face was in the RVF. We then compared half-face advantages in Experiment 1a to halfface advantages in Experiment $1 \mathrm{~b}$. Abnormally short response times (RTs) (less than $200 \mathrm{~ms}$ ) and outliers (defined as RTs more than 3 SD from the individual mean of each participant) were excluded from analysis.

\section{Method}

\section{Participants}

Required sample size was estimated based on the LVF half-face advantage effect size $(d=.54)$ reported by Coolican et al. (2008) for the young control group, which was demographically similar to our subject pool. According to $\mathrm{G}^{*}$ Power (Version 3.0; Faul, Erdfelder, Buchner, \& Lang, 2009) a sample size of 47 is required to detect an effect of this size at $\alpha=.05$ with a power of .95 using a paired-samples t-test. We therefore recruited 48 participants ( 27 female; mean age $=19.8$ years) from the University of Nevada, Reno. Five participants were graduate students who volunteered to participate in the study, and the others were undergraduate students who received course credit for participation. All observers were right-handed as assessed by the Edinburgh Handedness Inventory (Oldfield, 1971), and had normal or corrected-to-normal vision. The University of Nevada, Reno Institutional Review Board approved the experimental protocol. Prior to participating, each observer provided informed written consent. The same observers participated in Experiment 1a and Experiment 1b.

\section{Stimuli}

Experiment 1a Chimeric face stimuli were created from 51 faces (30 male) sourced from the Face-Place Database Project (Copyright 2008, Dr M. Tarr). All faces were forward-facing with neutral expression and cropped to remove hair cues. For Experiment 1a, the faces were mirrored, to create a set of 102 whole faces including the original orientation as well as a mirror-reversed copy. Each face was split at midline, and an LVF half-face chimera was made by combining the left half of the face with its mirror image, and an RVF half-face chimera was made by combining the right half with its mirror image. Stimuli were $2.5 \mathrm{~cm}$ in width and $3.8 \mathrm{~cm}$ in height, yielding visual angles of $2.5^{\circ}$ and $3.8^{\circ}$, respectively. Target faces were centered on the same point as the central fixation cross, and reference faces were centered $2^{\circ}$ above and below the central fixation cross.

Experiment $1 \mathrm{~b}$ For Experiment $1 \mathrm{~b}$, the 51 faces from the FacePlace Database used in Experiment 1a were split at midline, and the left half was mirrored, to create 51 pairs of mirrorsymmetric half-faces. From these half-faces, 100 chimeric faces composed of different left and right halves were created. These were then mirrored to create a set of 200 chimeric face stimuli. Stimulus size was the same as Experiment 1a. For both experiments, stimuli were presented on a Dell Precision T1650 (Intel Xeon E3 3.5 GHz), with 24-in. display and 1,920 $\times 1,200$ resolution. The stimuli were created and presented with the Psychophysics Toolbox v. 3.0.10 (Brainard, 1997) for MATLAB (Mathworks Inc., Natick, MA, USA) software package.

\section{Procedure}

Experiment 1a Participants were seated in front of the display with their chins set on a chin-rest, and viewed stimuli from 57 $\mathrm{cm}$. As shown in Fig. 1a, trials began with a central fixation cross $(500 \mathrm{~ms})$ followed by a centrally presented chimeric target face $(200 \mathrm{~ms})$, which was replaced with a mask (500 $\mathrm{ms}$ ) followed by two chimeric reference faces. The reference faces remained on the screen for up to $2,500 \mathrm{~ms}$ or until a response was recorded. Participants were instructed to respond via key press whether the top face was more similar to the target (with the "up" arrow) or the bottom face was more similar to the target (with the "down" arrow). LVF and RVF chimeric faces were equally likely to appear in the top or bottom. Participants completed 200 trials, and the trial sequence was randomized for each participant. 
a

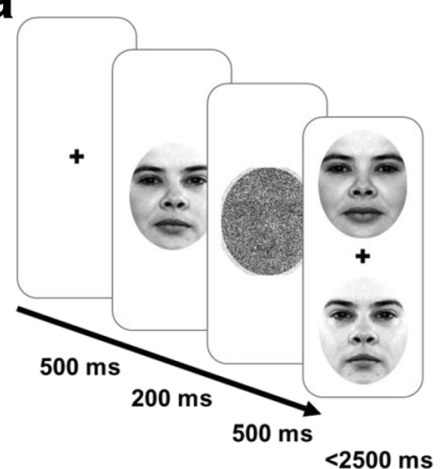

C

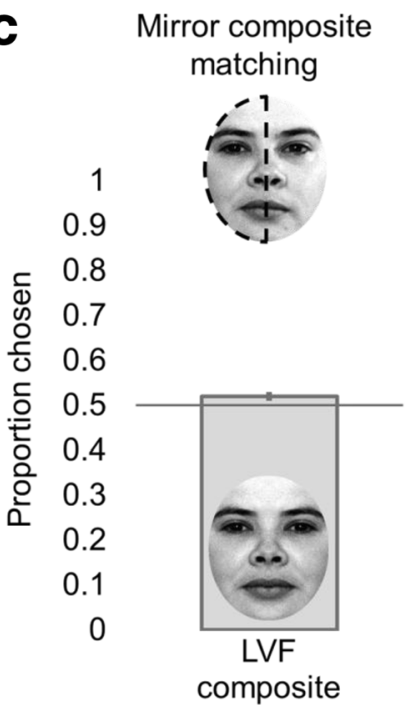

Fig. 1 (A) Trial sequence for Experiment 1a. Observers chose the reference face which most strongly resembled the target face. Each reference face was a mirrored composite of either the left (LVF) or right (RVF) half of the target face. (B) Trial sequence for Experiment 1b. Observers chose the reference face that matched the target. On each trial, reference faces differed in only one half of the face (either the LVF or RVF half). (C) In Experiment 1a, observers were more likely to match composites consisting of mirrored LVF face halves as compared to mirrored RVF face halves. Bar indicates that the mean proportion of left half-

Experiment 1b As shown in Fig. 1b, the procedure was identical to Experiment 1a, except that participants were instructed to respond via key-press whether the top face matched the target (with the "up" arrow) or the bottom face matched the target (with the "down" arrow). One of the reference faces was always identical to the target face, and the other differed from the target face in the LVF halfface or the RVF half-face. As a result of this design, either the LVF or RVF half-face was relevant for determining which reference face matched the target for each trial, and the contralateral half-face was not relevant to the task. Participants completed 100 trials in each condition, for 200 trials in total, and the trial sequence was intermixed and randomized for each participant. Stimulus images courtesy of Michael J. Tarr, Center for the Neural Basis
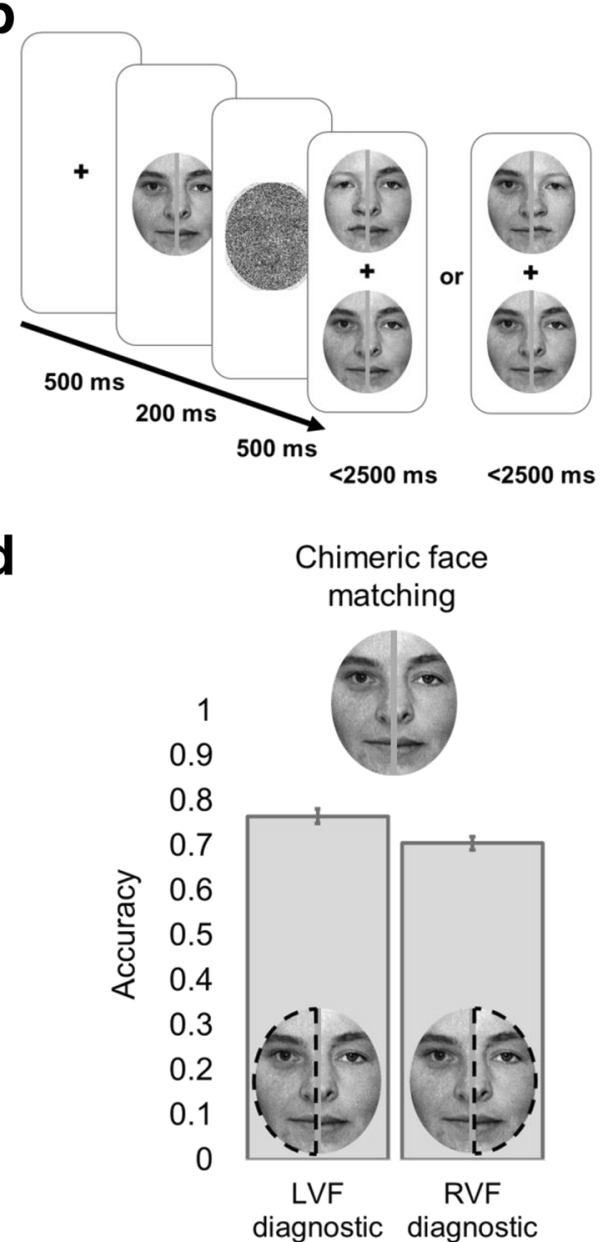

face composites chosen was significantly greater than 0.5 (gray line; $p<$ .001 ); the face shown within the bar was created by mirroring the left half of the face above the bar (dashed half-circle). (D) Bars indicate mean accuracy for reference faces matched using either the left or right facehalf. Accuracy was significantly $(p<.01)$ higher when the left (LVF) half of a face was used as compared to the right (RVF) half. Dashed half circles within each bar indicate which half of the face was relevant to performing the matching task

of Cognition and Department of Psychology, Carnegie Mellon University, http://www.tarrlab.org/. Funding provided by NSF award 0339122.

\section{Results and discussion}

For each individual, we computed the proportion of LVF/ RVF-based mirror reference faces chosen when matching the reference faces to the target (Experiment 1a). Although the majority of individuals ( $71 \%$ of the 48 participants) showed LVF/RVF $>.50$, many subjects did not, which is consistent with previously reported studies (Levine \& Levy, 1986; J. Levy, Heller, Banich, \& Burton, 1983b; Moreno, Borod, Welkowitz, \& Alpert, 1990). For the same individuals, we also computed mean 
accuracy in selecting the target face from the reference faces when target selection depended on either the LVF or RVF half-face (Experiment 1b). Sixty-three percent of the 48 observers showed greater accuracy for LVF halffaces than RVF half-faces (even fewer than for Experiment 1a), consistent with previous reports of this type of effect (Yovel et al., 2008).

\section{Experiment 1a}

We conducted group-level analysis to test whether the proportion of LVF/RVF based reference faces chosen was different than chance $(\mathrm{LVF} / \mathrm{RVF}=.50)$ and thus reflected an advantage for one half of a centrally viewed face. We identified an outlier $(\mathrm{LVF} / \mathrm{RVF}=.65)$, which was $>3 \mathrm{SD}$ from the group mean $(\mathrm{LVF} / \mathrm{RVF}=.52)$. Even when this participant's data were omitted, the mean group-level proportion of LVF-based references chose, shown in Fig. 1c, was significantly greater than chance; $t(47)=3.28, p=.002, d=.49$. These results are consistent with those of previous studies that reported a similarly weak LVF half-face advantage for normal centrally viewed faces, and its failure to occur in all subjects (Gilbert \& Bakan, 1973; Rhodes, 1985).

\section{Experiment 1b}

We conducted group-level analysis to test whether accuracy was greater when target face selection depended on the LVF or RVF half of a chimeric face. Mean group-level accuracy (shown in Fig. 1d) was higher for LVF half-faces $(M=.77$, $S D=.11)$ than for RVF half-faces $(M=.71, S D=.10) ; t(47)=$ $2.86, p=.007, \mathrm{~d}=.60$. Thus, although the LVF-advantage observed here was not strong, and not evident in all observers, our results are nevertheless consistent with previous observations of an LVF advantage for chimeric faces (Coolican et al., 2008; Gilbert \& Bakan, 1973; Schwartz \& Smith, 1980)

Both Experiment 1a and Experiment 1b showed an LVF half-face recognition advantage, despite differences in stimuli and task. To our knowledge, although the effect has been shown for both normal and chimeric faces, a relationship between the effect for the two types of stimuli and corresponding task differences has not been shown, although it has been inferred (Coolican et al., 2008; Yovel et al., 2008). We therefore performed a Pearson correlation to test for a relationship, and found a significant positive correlation between our measures of the LVF advantage in each experiment, $r(46)=.39, p$ $=.006$. This result is important because it suggests a shared underlying mechanism, which for chimeric faces is associated with a specific neural mechanism in the right hemisphere (Yovel et al., 2008). Additionally, our finding of a relationship also suggests that findings from the chimeric face matching paradigm used in Experiment $1 \mathrm{~b}$ generalize to normal faces, which is important here because manipulations in our remaining experiments depend on the use of this paradigm.

\section{Experiments $\mathbf{2 a}$ and $\mathbf{2 b}$}

In Experiments $1 \mathrm{a}$ and $1 \mathrm{~b}$ we found that the LVF half-face advantage for chimeric faces can serve as a proxy for the LVF advantage for normal centrally viewed faces. The purpose of Experiment 2a was twofold: First, to replicate previous findings that face inversion reduces or abolishes the LVF half-face advantage (Bourne, 2008, 2011; Butler \& Harvey, 2005), and to test whether or not upright RVF half-faces are recognized more easily than inverted half-faces; and second, to serve as a baseline for comparison with results from Experiment $2 b$ (and Experiment 3). The purpose of Experiment $2 b$ was to test whether recognition performance for individual half-faces viewed alone in the LVF will be better than for individual half-faces viewed alone in the RVF. We reasoned that obligatory LVF-RVF differences in face recognition ability should be observed whether or not a half-face is viewed alone or in the context of a normal (whole) face. We also reasoned that if a difference was not observed, this would mean that half-faces can be processed equally well in either visual field location, and that the LVF-half face advantage is rooted in simultaneous LVF/RVF face input rather than an inherent limitation of RVF face processing. We also included an inversion manipulation in Experiment $2 \mathrm{~b}$ as a baseline against which to assess LVFRVF upright half-face-recognition performance.

\section{Method}

\section{Participants}

Required sample size was estimated based on the LVF halfface advantage effect size observed in Experiment $1 \mathrm{~b}(d=.60)$, which was transformed following the approach of Cohen (1988) to $\eta^{2}=.08$. According to $G^{*}$ Power (Version 3.0; Faul, Erdfelder, Buchner, \& Lang, 2009) a sample size of 28 is required to detect an effect of this size at $\alpha=.05$ with a power of .95 for a $2 \times 2$ within-subject ANOVA. We therefore recruited 29 (19 female; mean age $=19.4$ years) participants from the University of Nevada, Reno. Twelve participants were graduate students who volunteered to participate in the study, and the others were undergraduate students who received course credit for participation. All observers were right-handed as assessed by the Edinburgh Handedness Inventory (Oldfield, 1971), and had normal or corrected-tonormal vision. The University of Nevada, Reno Institutional Review Board approved the experimental protocol. Prior to participating, each observer provided informed written consent. The same observers participated in Experiment 2a and Experiment 2b. 
a

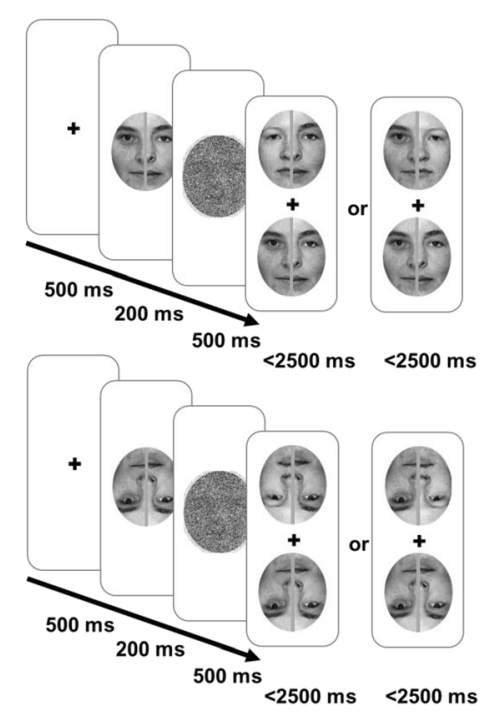

C

1

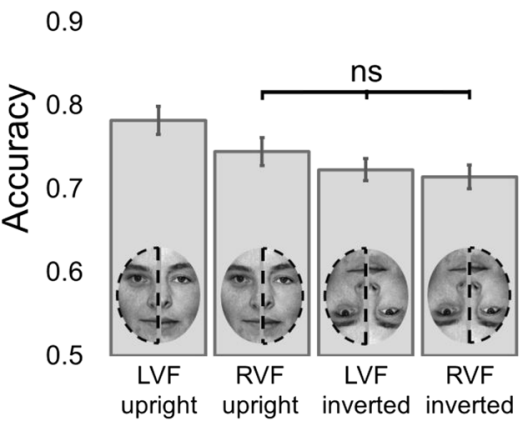

Fig. 2 (A) Trial sequence for Experiment 2a. Observers chose the reference face which matched the target. Reference faces differed on either the left (LVF) or right (RVF) half. Target and reference faces could be upright (top) or inverted (bottom). (B) Trial sequence for Experiment $2 b$. Observers chose the reference half-face which matched the target halfface. Target and reference half-faces appeared in either the LVF or RVF. Not shown is the sequence for inverted half-faces. (C) Bars indicate mean

\section{Stimuli}

Stimuli were identical to Experiment 1b, except that in Experiment 2a chimeric faces were either upright or inverted (Fig. 2a), and in Experiment 2b only LVF or RVF half-faces were presented, with the opposite side occluded by a shaded 3D box (Fig. 2b).

\section{Procedure}

Experiment 2a The procedure was identical to Experiment 1b, except on half the trials, where target and reference faces were upright, and on the other half, where they were inverted (see Fig. 2a). Conditions were defined by which face half was relevant to target selection (hemifield) and whether the faces were upright or inverted (inversion). Participants completed b

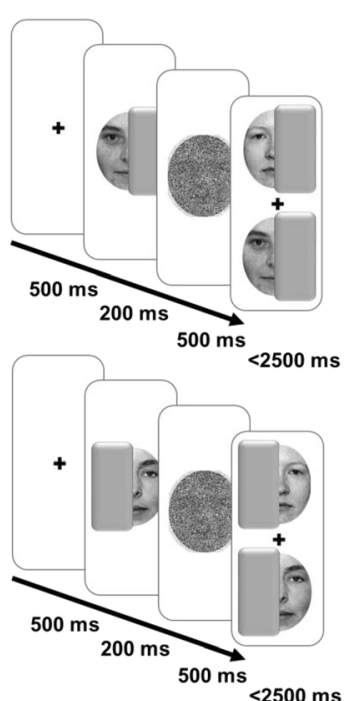

d

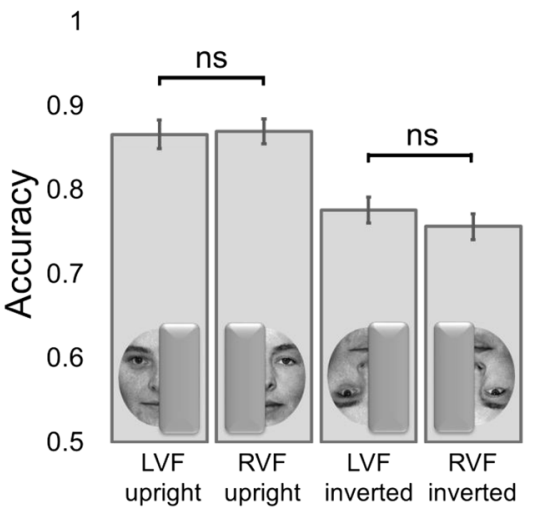

accuracy for upright and inverted reference faces matched using the LVF or RVF half. Mean accuracy for LVF upright half-faces was significantly higher than accuracy in all other conditions, $p<.01$. No other differences were significant. (D) Bars indicate mean accuracy for reference half-faces with the contralateral half occluded. There was no difference in mean accuracy for LVF and RVF half-faces when a contralateral half-face was not present

100 trials in each condition, for 400 trials in total, and the trial sequence was intermixed and randomized for each participant.

Experiment $2 \mathrm{~b}$ As shown in Fig. 2b, the procedure was identical to Experiment 2a, except target and reference faces were always either a LVF or RVF half-face, with the opposite side occluded by a shaded 3D box. On half of the trials, the target and reference faces were upright, and on the other half they were inverted.

\section{Results and discussion}

For each participant, we computed mean accuracy in selecting the target face from the reference faces when target selection depended on LVF or RVF half-faces in upright and inverted chimeric faces. $72 \%$ of the 29 observers showed greater 
accuracy for upright LVF half-faces as compared to upright RVF half-faces when faces were upright, more than we reported for Experiment $1 \mathrm{~b}$. Crucially, $48 \%$ showed greater LVF than RVF accuracy when faces were inverted, which is consistent with an absence of the LVF advantage for inverted faces when considering how many observers show an RVFLVF difference. Subsequent group-level analyses confirmed the presence of an LVF advantage for upright but not inverted faces. For each participant we also computed mean accuracy for upright and inverted LVF and RVF half-faces viewed with the contralateral half occluded. Out of 29 participants, $48 \%$ showed greater accuracy for upright LVF than upright RVF half-faces, and 59\% showed greater accuracy for inverted LVF than inverted RVF half-faces. There was thus no evidence of an LVF half-face advantage for upright half-faces viewed alone (and if anything, a modest LVF advantage for inverted faces, which failed to extend to group-level results reported next).

Group-level accuracy data were analyzed using a 2 (experiment: non-occluded, half-occluded) $\times 2$ (orientation: upright, inverted) $\times 2$ (hemifield: LVF, RVF) repeated-measures ANOVA. We found that the three-way interaction between experiment, orientation, and hemifield was significant, $F(1$, 28) $=10.09, p=.004, \eta^{2}=.27$. To simplify interpretation of our results, we therefore ran separate ANOVAs on the nonoccluded (Experiment 2a) and half-occluded (Experiment 2b) face conditions, which are detailed in the following sections.

To determine whether there was an overall difference in accuracy between non-occluded and half-occluded conditions, we computed average accuracy for each participant in Experiment $2 \mathrm{a}$ and Experiment $2 \mathrm{~b}$ and performed a pairedsamples t-test on the resulting mean accuracy scores. This revealed that mean accuracy was higher for half-occluded faces $(M=.82, S D=.071)$ than for non-occluded faces $(M=$ $.75, S D=.054): t(28)=5.88, p<.001, d=.92$. The difference in accuracy means that response differences between the two experiments could be due at least in part to lower task difficulty in matching half-occluded faces compared to nonoccluded faces.

\section{Experiment 2a}

Mean group-level accuracy is shown in Fig. 2c. Consistent with the LVF half-face advantage previously observed, accuracy was higher for upright LVF half-faces than for upright RVF half-faces (LVF upright: $M=.80, S D=.083$; RVF upright: $M=.76, S D=.077)$. Consistent with a detrimental effect of inversion on face recognition, accuracy was lower for inverted faces than for upright faces (LVF inverted: $M=.73$, $S D=.064$; RVF inverted: $M=.73, S D=.063)$. Accuracy data were analyzed using a 2 (upright, inverted) $\times 2(\mathrm{LVF}, \mathrm{RVF})$ repeated-measures ANOVA, which revealed a main effect of inversion (upright accuracy $>$ inverted accuracy: $F(1,28)=$
12.90, $\left.p<.001, \eta^{2}=.32\right)$, but no main effect for hemifield $\left(F(1,28)=3.21, p=.084, \eta^{2}=.10\right)$. The interaction between hemifield and inversion was significant $(F(1,28)=7.12, p=$ $\left..013, \eta^{2}=.20\right)$, so we performed Bonferroni-corrected pairedsample t-tests, which showed that mean accuracy was higher for LVF upright half-faces than for RVF upright half-faces, $t(28)=2.84, p=.008, d=.68$. Mean accuracy for LVF upright half-faces was also higher than for LVF inverted half-faces $(t(28)=4.86, p<.001, d=.99)$, and RVF inverted halffaces $(t(28)=3.64, p=.001, d=.79)$. There was no difference in mean accuracy between LVF inverted and RVF inverted half-faces, $t(28)=-.27, p=.75 d=.05$. There was also no difference in accuracy between RVF upright half-faces and LVF inverted half-faces $(t(28)=2.02, p=.053, d=.41)$ or RVF inverted half-faces $(t(28)=1.63, p=.11, d=.37)$. Taken together, these results indicate a LVF half-face advantage for upright faces but not for inverted faces, and no advantage for upright RVF over inverted LVF or RVF half-faces.

We next examined the effect of face inversion, defined as inverted half-face accuracy subtracted from upright half-face accuracy, on LVF and RVF half-faces. A paired-samples t-test showed that the effect of face inversion was greater for LVF half-faces $(\mathrm{M}=.07, \mathrm{SD}=.07)$ than for RVF half-faces $(\mathrm{M}=$ $.03, \mathrm{SD}=.09), t(28)=2.69, p=.013, d=.50)$. One-sample ttests showed that the face inversion effect for LVF half-faces was significantly different from $0(t(28)=4.86, p<.001, d=$ $.89)$, but the face inversion effect for RVF half-faces was not $(t(28)=1.63, p=.11, d=.37)$. This suggests that when both halves of a face are present, the face inversion effect only occurs for LVF half-faces.

\section{Experiment 2b}

Mean group-level accuracy for individually viewed (halfoccluded) half-faces is shown in Fig. 2d. Individual half-face accuracy was highest for upright half-faces, and accuracy for upright RVF half-faces $(M=.87, S D=.081)$ was similar to accuracy for upright LVF half-faces $(M=.87, S D=.092)$. Accuracy was lowest for inverted half-faces, with accuracy for inverted RVF half-faces $(M=.75, S D=.082)$ slightly lower than accuracy for inverted LVF half-faces $(M=.77$, $S D=.087$ ). Accuracy data were analyzed using a 2 (upright, inverted) $\times 2(\mathrm{LVF}, \mathrm{RVF})$ repeated-measures ANOVA, which revealed a main effect of inversion, (upright accuracy $>$ inverted accuracy: $\left.F(1,28)=84.47, p<.001, \eta^{2}=.74\right)$, and no main effect of hemifield $(F(1,28)=.68, p=.41)$. The interaction between inversion and hemifield was also not significant $(F(1,28)=1.54, p=.22)$. In short, our statistical analyses showed no evidence of an LVF half-face recognition advantage for half-occluded upright or inverted faces.

We next examined the effect of face inversion (inverted accuracy subtracted from upright accuracy) for halfoccluded chimeric faces. A paired-samples t-test showed no 
evidence of a difference between the effect of face inversion for LVF half-faces $(\mathrm{M}=.10, \mathrm{SD}=.07)$ and RVF half-faces (M $=.13, \mathrm{SD}=.08), t(28)=2.69, p=.013, d=.50)$. One-sample t-tests showed that the face inversion effect was significantly greater than 0 for both LVF half-faces $(t(28)=7.06, p<.001, d$ $=.94)$, and RVF half-faces $(t(28)=8.26, p<.001, d=1.56)$. This shows that the face inversion effect occurs for LVF and RVF half-faces to an equivalent degree when individual halffaces are presented alone.

In summary, the results of Experiments $2 \mathrm{a}$ and $2 \mathrm{~b}$ showed that occluded faces fail to show an LVF advantage, but nevertheless show an inversion effect. Despite the finding of an inversion effect, it is possible that the absence of an LVF advantage relates to the increased accuracy observed in Experiment $2 \mathrm{~b}$ relative to the same subjects in Experiment 2a. The likely source of this accuracy increase was the lack of uncertainty about which half-faces (LVF or RVF) were relevant to the matching task. We addressed this in the next experiments.

\section{Experiment 3}

The purpose of this experiment was to test whether lack of uncertainty about which side of a face stimulus is task relevant a

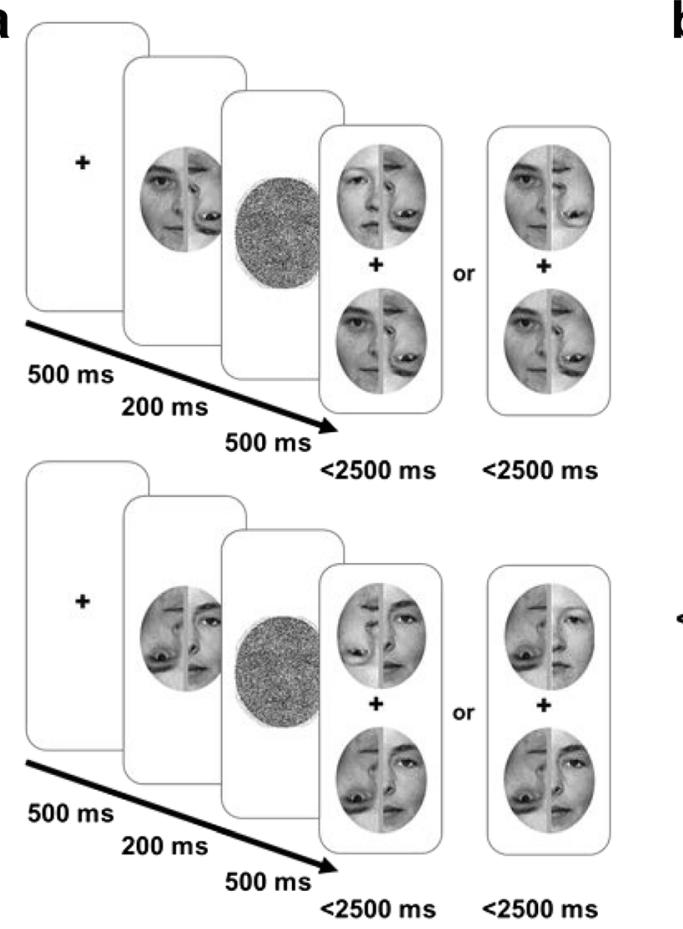
face that matched the target face. Target and reference faces were composed of one upright and one inverted half-face. Reference faces differed in either the left (LVF) or right (RVF) half. The task-relevant half of the reference faces was equally likely to be upright or inverted. The top sequence shows upright LVF and inverted RVF task-relevant half-face
Fig. 3 (A) Trial sequence in Experiment 3. Observers chose the reference sufficiently accounts for the absence of an LVF half-face bias in Experiment 2b. In Experiment 3 we therefore designed chimeric face stimuli consisting of an upright half-face paired with an inverted half-face and viewed simultaneously, as shown in Fig. 3a. This experiment was run on a subset of observers who participated in Experiments $2 \mathrm{a}$ and $2 \mathrm{~b}$. To serve as a baseline for comparison, we conducted an analysis of Experiment 2a restricted to the subset of participants in Experiment 3.

\section{Method}

\section{Participants}

Required sample size was estimated based on the hemifield $x$ orientation interaction effect size observed in Experiment 2a $\left(\eta^{2}=.20\right)$. According to $G^{*}$ Power (Version 3.0; Faul, Erdfelder, Buchner, \& Lang, 2009) a sample size of 12 is required to detect an effect of this size at $\alpha=.05$ with a power of .95 for a $2 \times 2$ within-subject ANOVA. We nevertheless recruited as many of the subjects who had participated in Experiments $2 \mathrm{a}$ and $2 \mathrm{~b}$ as were available, to better serve as a comparison to these experiments. Nineteen (12 female; mean age $=19.1$ years) observers, who were a subset of participants who took part in Experiments $2 \mathrm{a}$ and $2 \mathrm{~b}$, participated in

b
0.9

0.8

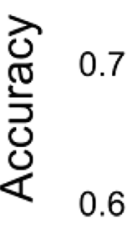

0.5

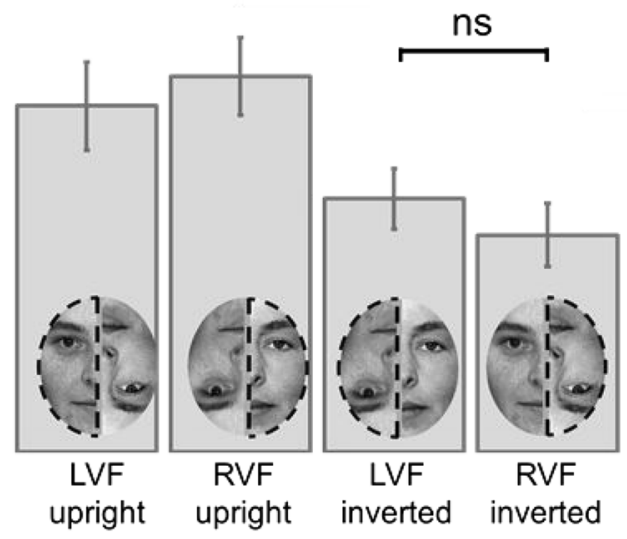

conditions, and the lower sequence shows inverted LVF and upright RVF task-relevant half-face conditions. (B) Bars indicate mean accuracy for reference faces matched using either upright or inverted half-faces in the LVF or RVF. When only one upright half-face was present in a chimeric face, recognition accuracy was equivalent for upright LVF and RVF halffaces 
Experiments 3. Four participants were graduate students who volunteered to participate in the study, and the others were undergraduate students who received course credit for participation. All criteria were the same as for Experiments $2 \mathrm{a}$ and $2 \mathrm{~b}$.

\section{Materials}

Stimuli for Experiment 3 were identical to stimuli for Experiment 2a, except the LVF or RVF half of the chimeric target and reference faces were inverted, such that each chimeric face consisted of one upright and one inverted half-face (see Fig. 3a).

\section{Procedure}

As shown in Fig. 3a, the procedure for Experiment 3 was identical to Experiment 2a, except that face stimuli were composed of mixed upright and inverted half-faces. Target selection was equally likely to depend on the inverted half-face as the upright half-face.

\section{Results and discussion}

For each participant, we computed mean accuracy in selecting the target face from the reference faces when target selection depended on LVF or RVF half-faces in chimeric faces composed of one upright and one inverted half-face. Out of 19 participants, $47 \%$ showed greater accuracy for upright LVF than upright RVF half-faces, and $42 \%$ showed greater accuracy for inverted LVF than inverted RVF half faces. Thus, there is no evidence of an LVF half-face advantage for upright halffaces viewed with an inverted half-face in the contralateral visual hemifield. To serve as a baseline for comparison to Experiment 3, we also conducted an analysis of Experiment $2 \mathrm{a}$ restricted to the subset of observers who participated in Experiment 3. Our goal was to confirm that the pattern of results observed in Experiment 2a was the same for the participants in Experiment 3. Seventy-nine percent of the $19 \mathrm{ob}-$ servers showed greater accuracy for upright LVF than upright RVF half-faces, and 53\% showed greater accuracy for inverted LVF than inverted RVF half faces. This was similar to the proportion reported in the full set of observers, and replicated the indication of an LVF bias for upright but not inverted half-faces. Across all of our experiments, the only condition under which more than $60 \%$ of observers showed an LVF advantage was when a chimeric face consisted of two upright half-faces in the LVF and RVF.

Group-level accuracy data were analyzed using a 2 (experiment: mixed upright and inverted, non-mixed baseline $) \times 2$ (orientation: upright, inverted) $\times 2$ (hemifield: LVF, RVF) repeated-measures ANOVA. We found that the three-way interaction between experiment, orientation, and hemifield was significant, $F(1,18)=9.23, p=.007, \eta^{2}=.34$. To simplify interpretation of our results, we therefore ran separate ANOVAs on the mixed upright and inverted (Experiment 3) and non-mixed (baseline) face conditions.

To determine whether there was an overall difference in accuracy between mixed upright and inverted and nonmixed chimeric face conditions, we computed average accuracy for each participant in Experiment 3 and the baseline and performed a paired-samples t-test on the resulting mean accuracy scores. This revealed that mean accuracy was lower for mixed upright and inverted faces $(M=.71, S D=.071)$ than for non-mixed faces $(M=.75, S D=.047): t(18)=3.35, p=.004$, $d=.66$. This means that the increased accuracy in Experiment $2 \mathrm{~b}$ was successfully controlled for. In fact, matching half-faces in mixed upright and inverted chimeric faces is more difficult than matching half-faces in standard chimeric faces. We conclude from this that a lack of an LVF advantage for upright half-faces when they are paired with inverted half-faces could not be due to lower task difficulty.

As shown in Fig. 3b, when upright half-faces were paired with inverted half-faces (mixed upright and inverted halffaces), mean group-level accuracy was highest for mixed upright half-faces, and accuracy for mixed upright LVF halffaces $(M=.75, S D=.14)$ was similar to accuracy for mixed upright RVF half-faces $(M=.77, S D=.12)$. Accuracy was lowest for mixed inverted half-faces, with accuracy for mixed inverted RVF half-faces $(M=.65, S D=.09)$ slightly lower than accuracy for mixed inverted LVF half-faces $(M=.68, S D$ $=.09$ ). Accuracy data were analyzed using a 2 (upright, inverted) $\times 2(\mathrm{LVF}, \mathrm{RVF})$ repeated-measures ANOVA, which revealed a main effect of inversion (upright accuracy $>$ inverted accuracy: $\left.F(1,18)=11.60, p=.003, \eta^{2}=.39\right)$, no main effect of hemifield $\left(F(1,18)=.003, p=.93, \eta^{2}<.001\right)$, and no interaction between hemifield and inversion $(F(1,18)$ $\left.=3.76, p=.07, \eta^{2}=.17\right)$. This means that when only one upright half-face is present, there is no LVF advantage for upright half-faces, even when they are paired with inverted half-faces in the contralateral visual field that are equally task-relevant.

Group-level analysis of our baseline condition, a subset of Experiment 2a restricted to the participants in Experiment 3, showed accuracy was higher for upright LVF half-faces than for upright RVF half-faces (LVF upright: $M=.80, S D=.09$; RVF upright: $M=.74, S D=.07$ ), and accuracy was lower for inverted faces than for upright faces (LVF inverted: $M=.73$, $S D=.06$; RVF inverted: $M=.73, S D=.07)$. Accuracy data were analyzed using a 2 (upright, inverted) $\times 2$ (LVF, RVF) repeated-measures ANOVA, which revealed a main effect of inversion (upright accuracy $>$ inverted accuracy: $F(1,18)=$ $\left.7.18, p=.015, \eta^{2}=.28\right)$, a main effect of hemifield (LVF accuracy > RVF accuracy: $F(1,18)=9.10, p=.007, \eta^{2}=$ $.34)$, and an interaction between hemifield and inversion $\left(F(1,18)=7.23, p=.015, \eta^{2}=.29\right)$. Bonferroni-corrected 
paired-sample t-tests showed that mean accuracy was higher for LVF upright half-faces than for RVF upright half-faces, $t(18)=3.63, p=.002, d=.75$. Mean accuracy for LVF upright half-faces was also higher than for LVF inverted half-faces $(t(18)=3.79, p=.001, d=.90)$, and RVF inverted halffaces $(t(18)=3.47, p=.003, d=.94)$. There was no difference in mean accuracy between LVF inverted and RVF inverted half-faces, $t(18)=.23, p=.82, d=.09$. There was also no difference in accuracy between RVF upright half-faces and LVF inverted half-faces $(t(18)=.54, p=.60, d=.12)$, or RVF inverted half-faces $(t(18)=.61, p=.55, d=.20)$. This verified that the subset of observers who participated in Experiment 3 showed the same pattern of results in Experiment $2 \mathrm{a}$ as the whole set of participants.

In summary, we found that upright LVF and RVF halffaces were recognized equally well when they were paired with inverted half-faces, despite a decrease in accuracy when upright and inverted half-faces are paired.

\section{General discussion}

The main purpose of our study was to test whether RH superiority of face processing sufficiently explains the LVF halfface advantage in face recognition or not. Our results successfully demonstrated the generalizability of the LVF half-face advantage from normal to chimeric faces. We also showed for the first time that the LVF half-face advantage observed for each type of stimulus is associated with impaired processing of RVF half-faces, contingent on the presence of an upright LVF half-face. Importantly, however, we also found that RVF face halves can sometimes be recognized just as well as LVF face halves. The logic of the divided field paradigm (Bourne, 2006) - a major source of evidence in favor of RH superiority in relation to the LVF advantage in face recognition - assumes that stimulus information in each visual field is initially projected to and processed by visual cortex in the contralateral hemisphere. Our results therefore suggest that the LH can process the RVF half of a face just as well as the RH processes the LVF half of a face, but only under specific conditions. We conclude that RH superiority coupled with a contralateral LVF-RH relationship, a prevailing explanation of the LVF advantage for face recognition (Gilbert \& Bakan, 1973; J. Levy et al., 1983b; Rhodes, 1985; Sergent \& Bindra, 1981; Yovel et al., 2003), does not suffice to explain the LVF advantage in face recognition.

\section{Normal and chimeric faces}

One of our first objectives was to verify the occurrence of the LVF half-face advantage in both normal and chimeric faces. Many studies have reported the LVF half-face advantage in either normal faces (Brady et al., 2005; Gilbert \& Bakan,
1973; Kolb, Milner, \& Taylor, 1983) or chimeric faces (Levy, Trevarthen, \& Sperry, 1972; Milner \& Dunne, 1977; Schwartz \& Smith, 1980), but did not test the effect in both. An exception to this is a study by Coolican et al., (2008), which reported an LVF advantage in both normal and chimeric faces, but did not show an explicit relationship between the LVF advantage for each. It was therefore important to show that the LVF half-face advantage occurs for both types of stimuli, and corresponding tasks, to justify the use of chimeric faces in our experiments, and the generalization of our results to normal faces. While the same RH mechanism has been proposed to underlie the LVF advantage in both types of half-face effects (Bourne, 2011; Coolican et al., 2008; Luh, 1998; Schwartz \& Smith, 1980), we were the first to test for a common mechanism explicitly. We observed an LVF half-face advantage in both normal whole faces (Experiment 1a) and chimeric faces (Experiment 1b), in the same group of subjects, and a corresponding positive correlation in the degree of LVF advantage. While we cannot be certain that this reflects the involvement of a common mechanism for the LVF half-face advantage in both normal and chimeric faces, this possibility is plausible and implicit in other accounts of the LVF advantage in chimeric face recognition (e.g., Coolican et al., 2008).

It is worth noting that LVF half-face advantage was neither large nor apparent in all of the observers we tested. This general finding is consistent with those reported in previous studies (e.g., Coolican et al., 2008; Gilbert \& Bakan, 1973; Rhodes, 1985; Yovel et al., 2003). Given the view that face processing mechanisms are typically right lateralized (Kanwisher et al., 1997; Puce, Allison, Asgari, Gore, \& McCarthy, 1996; Sergent, Ohta, \& Macdonald, 1992), this alone may appear to undermine the validity of RH superiority as a sufficient explanation of the LVF half-face advantage. However, recent studies have reported that the fusiform face area (FFA), which is commonly referred to as a major cerebral component of right-hemisphere involvement in face recognition and a plausible basis for right-hemisphere superiority in face processing, also shows variability or absence of rightlateralization (Bukowski, Dricot, Hanseeuw, \& Rossion, 2013; Yovel et al., 2008). Furthermore, the study by Yovel et al. reported a correlation between the strength of the LVF half-face advantage and the degree of right-lateralization of the FFA, which they proposed as the precise neural basis of the behavioral effect.

\section{Interpreting the effects of inversion and occlusion}

RH superiority in face processing is a prevailing explanation of LVF advantages in face recognition, for both centrally and peripherally viewed faces (Bourne, 2011; Cattaneo et al., 2014; Coolican et al., 2008; Hillger \& Koenig, 1991; Luh, 1998; Parkin \& Williamson, 1987). Whether or not RH superiority alone is sufficient to explain these LVF advantages is 
not known. We therefore measured face-recognition performance, and its disruption by inversion (Farah, Tanaka, \& Drain, 1995; Freire et al., 2000; Leder \& Bruce, 2000), in each hemifield, independently. We reasoned that if the LVF halfface advantage is due to superior visual processing of spatial relations by the RH (Hillger \& Koenig, 1991; Martinez et al., 1997; Rossion et al., 2000; Sergent, 1982a; Van Kleeck, 1989), then the detrimental effect of inversion on face recognition should be greater for the LVF half of a face as compared to the RVF half. Furthermore, we reasoned that this would occur even when each half of a face is viewed alone (i.e., the other half is occluded), especially if visual processing of spatial relations is important for the recognition of parts (i.e. halves) of faces (James, Arcurio, \& Gold, 2013) and holistic face processing occurs even for half-faces viewed in isolation (Sadr \& Krowicki, 2019). Although previous studies reported that face inversion reduced or eliminated the LVF half-face advantage (Bourne, 2008, 2011; Butler \& Harvey, 2005; Coolican et al., 2008), these studies did not measure the effects of inversion separately in each hemifield.

We anticipated one of two possibilities, either a reduced inversion effect in the RVF or an absence of it altogether in the RVF. In Experiment $2 \mathrm{a}$ we confirmed previous reports that the LVF half-face advantage is eliminated for inverted faces. We also found that the ability to recognize an upright versus inverted RVF half-face is the same in each case. Indeed, relative to recognition of upright LVF half-faces, recognition of upright RVF half faces was as impaired as recognition of inverted halffaces in either hemifield. This suggests that the LVF advantage reflects superior processing of spatial relations that does not occur for RVF half-faces. If we had found a weaker but significant inversion effect in the RVF, then we still would have concluded that the LVF advantage reflects an inherent deficit, but not an absence (Cattaneo et al., 2014), of spatial relations processing in the RVF. This highlights the interesting possibility that the LVF half-face advantage reflects a deficit of spatial relations processing by the LH for the RVF half of a face which, crucially, only arises in the presence of a simultaneously viewed LVF upright half-face. It is possible that the occluded face halves are perceptually completed across midline, thus creating a symmetric amodally completed whole face, which might enable the equivalent RVF and LVF half-face-recognition performance in Experiment $2 b$. However, the presence of a RVF upright half-face in Experiment 1a, and inverted half-faces in Experiment 3, apparently negates this possibility.

It is worth noting that face-recognition performance (accuracy) was higher in Experiment $2 b$ relative to $2 a$ (due to decreased location uncertainty for the matching task). We controlled for this in Experiment 3 by using upright half-faces paired with inverted half-faces, in opposite locations (RVF or
LVF), which also ensured that only one half of a face could be processed optimally. Even after controlling for task demands (accuracy was more similar between Experiments 2a and 3 as compared to Experiments $2 \mathrm{a}$ and $2 \mathrm{~b}$; accuracy was actually modestly lower in Experiment 3 as compared to 2a), we still failed to observe the LVF half-face advantage. Importantly, the results of Experiment 3 showed that RVF half-face recognition can equal that of the LVF, and that this is due to a recovery of upright RVF half-face processing when the LVF half of a face is inverted, in addition to when it is absent (Experiment $2 \mathrm{~b}$ ). We interpret this as evidence that the LVF half-face advantage reflects a deficit in processing the RVF half of a face - whereby the RVF half of an upright face is processed equally poorly as an inverted half-face in either visual hemifield - but that this deficit only occurs in the presence of a simultaneously viewed upright LVF half-face. That is, the LVF advantage reported here may reflect a spatial relations processing deficit for RVF face stimuli, as reported by others (Cattaneo et al., 2014; Hillger \& Koenig, 1991; Parkin \& Williamson, 1987; Ramon \& Rossion, 2012; Rossion et al., 2000; Sergent, 1982a), but this deficit is not obligatory under all conditions, which one might expect if the deficit reflects a corresponding inter-hemispheric difference in visual processing per se.

The processing of spatial relations between the constituent parts of a face is thought to be particularly important for face recognition (Bartlett, Searcy, \& Abdi, 2003; Diamond \& Carey, 1986; Leder \& Bruce, 2000; Leder \& Carbon, 2006; Rhodes, 1993; Searcy \& Bartlett, 1996), and is widely thought to be an essential component of holistic face processing, the global processing of faces as a perceptually unified whole (Cheung, Richler, Palmeri, \& Gauthier, 2008; Maurer et al., 2002; Mckone \& Yovel, 2009). Because face inversion has been shown to disrupt spatial relations processing within a face (Barton, Keenan, \& Bass, 2001; Collishaw \& Hole, 2000; Goffaux \& Rossion, 2007; Rhodes, Brake, \& Atkinson, 1993), the impairment of face recognition caused by inversion is often taken to be a marker of holistic processing (Farah et al., 1995; Tanaka \& Farah, 1993; Van Belle, De Graef, Verfaillie, Rossion, \& Lefevre, 2010). However, interpretations of holistic processing drawn from face inversion effects require some caution, because inversion does not directly manipulate holistic processes (Tanaka \& Simonyi, 2016). Since our manipulations involved faces only, and no other object classes to serve as a control, we are limited in our ability to interpret our results in terms of face-specific types of processing. We do not view this limitation as a major weakness in our study because we were primarily interested in finding LVF/RH-RVF/LH differences (Experiments $1 \mathrm{a}, 1 \mathrm{~b}$ and $2 \mathrm{a}$ ) and equivalences (Experiments $2 \mathrm{~b}$ and 3 ) in face processing, regardless of 
the specific type of visual processing underlying recognition performance.

\section{RH superiority and LVF advantages}

LVF advantages in face recognition are ubiquitous, especially in the context of the divided field paradigm. The logic of divided visual field studies is that face information in each visual field is initially projected to and processed by visual cortex in the contralateral hemisphere (Bourne, 2006). Typically, divided field studies of face recognition involve the use of peripherally viewed faces (Dundas et al., 2013; Hellige, Corwin, \& Jonsson, 1984; Hellige, Jonsson, \& Michimata, 1988; Hillger \& Koenig, 1991; Hilliard, 1973; Klein, Moscovitch, \& Vigna, 1976; Marzi \& Berlucchi, 1977; Parkin \& Williamson, 1987; Perrett, Rolls, \& Caan, 1982; Rizzolatti \& Buchtel, 1977; Rizzolatti et al., 1971). Neural populations in the right hemisphere - such as the FFA - associated with specialized face processing (e.g., those in right fusiform cortex) show a contralateral (LVF) visual field bias (Hemond, Kanwisher, \& Op de Beeck, 2007; Sayres \& Grill-Spector, 2008). The FFA has been implicated in holistic processing of spatial relations (Rossion et al., 2000; Schiltz \& Rossion, 2006), which combined with its contralateral bias may explain the LVF advantage for peripherally viewed faces in divided field experiments, although it is possible that other face-selective regions in the right hemisphere are also involved.

Whether or not the LVF bias for face-processing mechanisms in the right hemisphere sufficiently explains the LVF half-face advantage is less clear. A combined behavioral and neuroimaging study by Yovel, Tambini and Brandman (2008) explicitly implicates the FFA as underlying the LVF half-face advantage, which highlights the possibility of a common underlying mechanism for LVF advantage reported for both peripherally and centrally viewed faces. Neural populations in the FFA that underlie face processing and exhibit an LVF bias also show a foveal bias (Hasson, Levy, Behrmann, Hendler, \& Malach, 2002; I. Levy, Hasson, Avidan, Hendler, \& Malach, 2001), which may explain why faces are most easily recognized when viewed centrally (Mäkelä, Näsänen, Rovamo, \& Melmoth, 2001), and tend to be fixated during the recognition process (Hsiao \& Cottrell, 2008). More detailed studies of FFA sensitivity to faces viewed at different locations in the visual fields report maximal sensitivity in a region of the LVF near vertical midline (Kay, Weiner, \& Grill-Spector, 2015). This means that, like the LVF advantage for peripherally viewed whole faces, the LVF half-face advantage may too involve an LVF advantage, albeit closer to the center of gaze. Taken together with other evidence of a contralateral hemifield-hemisphere relationship for hemifield-split stimuli splitting (Hsiao \& Shillcock, 2005; Hunter, Brysbaert, \& Knecht, 2007; Lavidor \& Ellis, 2003), even for stimulus information within $1^{\circ}$ of the vertical meridian (Lavidor \& Walsh, 2004; Lindell \& Nicholls, 2003), this validates reference to the logic of the divided field paradigm for centrally viewed chimeric faces (Bourne, 2008, 2011; Brady et al., 2005; Burt \& Perrett, 1997; Coolican et al., 2008; Gilbert \& Bakan, 1973; Luh, 1998; Luh et al., 1991; Schwartz \& Smith, 1980; Yovel et al., 2008).

Despite the plausibility of a common mechanism underlying the LVF bias for faces viewed centrally and peripherally, the results of our experiments complicate this view. In our study, we found that for half-faces viewed alone, in either the RVF or the LVF, equivalent recognition accuracy and inversion effects occurred in each location. We interpret this as indicative of equivalent processing of spatial relations for RVF and LVF half-faces viewed in isolation. Previous studies using a face inversion manipulation have reported that holistic processing of spatial relations can occur for peripherally viewed faces in both hemifields (Kovács, Knakker, Hermann, Kovács, \& Vidnyánszky, 2017), but is greater in the LVF than the RVF (Cattaneo et al., 2014; Hillger \& Koenig, 1991; Leehey, Carey, Diamond, \& Cahn, 1978). Our finding of equivalent processing for RVF and LVF halves of centrally viewed faces when viewed alone suggests that greater face-processing resources are available for centrally viewed faces as compared to peripherally viewed faces. This is important to note because it means that unlike the LVF advantage for faces viewed in the periphery, the LVF halfface advantage for centrally viewed faces may not be solely explained by RH superiority coupled with the assumed LVFRH mapping, as proposed originally and in a study of the neural basis of the effect (Gilbert \& Bakan, 1973; Yovel et al., 2008). That is, in contrast to the LVF advantage for peripherally viewed faces, the LVF half-face bias may arise as the result of a limitation in applying face-processing resources simultaneously to hemifield-split half-faces rather than an inherent deficit of processing of RVF face stimuli by the $\mathrm{LH}$.

\section{LVF half-face prioritization}

Our finding that the RVF half of a face can be processed as well as the LVF half of a face, but only when the LVF half is not present, is consistent with findings that the RVF and LVF halves of a centrally viewed face are processed interactively (Boremanse, Norcia, \& Rossion, 2014; Hole, 1994; Yovel et al., 2005), such that processing of one face half depends on that of the other. This might be due in part to the two halves of a centrally viewed face competing with one another for specialized face recognition resources, in the same way whole faces do (Gentile \& Jansma, 2010; Jacques \& Rossion, 2004). It is plausible that the presence of an upright LVF half-face biases this competition by allocating face-processing resources to the LVF at the expense of RVF face processing, 
even though equivalent half-face processing is possible for the RVF half of a face when viewed alone. A study by Liu, Hayward, Oxner, and Behrmann (2014) found equivalent holistic processing effects for LVF and RVF halves of centrally viewed faces. Their results are consistent with ours from Experiments $2 b$ and 3, for which we observed no differences in recognition performance, but the equivalent LVF and RVF holistic processing they observed contrasts with our finding of an LVF advantage for centrally viewed upright whole faces. However, the paradigm they used depended on cuing either LVF or RVF half-faces, which would be consistent with the biasing of attention toward the LVF or RVF by the presence of only one half face (Experiment $2 \mathrm{~b}$ ) or the pairing of an upright and inverted half-face (Experiment 3). A resource allocation explanation would thus reconcile the results of our experiments with those of Liu et al.

Our experiments did not manipulate attention, so we can only speculate about a potential role of attention in our results. A possible role of visual attention has been acknowledged in previous studies of the LVF half-face advantage because it exhibits an inherent LVF bias for faces and non-face stimuli (J. Levy, Heller, Banich, \& Burton, 1983a; Luh et al., 1991; Yovel et al., 2008), in both cerebral hemispheres (Siman-Tov et al., 2007). Additionally, learned attentional biases related to the development of holistic face processing (Richler, Palmeri, \& Gauthier, 2012), and object recognition expertise more generally (Chua, Richler, \& Gauthier, 2014, 2015), could be instantiated with respect to LVF face parts (Chua \& Gauthier, 2016). Such a bias might only occur when a whole "configurally intact" face is viewed, consistent with holistic processing of whole faces, which would be in line with our findings from Experiments $2 b$ and 3 . If so, the prioritization of LVF face processing would reflect a means of optimizing allocation of limited face-processing resources, especially those in the RH. Whether prioritization of LVF half-face processing is the product of a learned attention mechanism, or an alternative mechanism, we propose that it is necessary to account for the LVF half-face bias, in addition to the coupling of RH superiority and LVF-RH correspondence.

This proposal is also relevant to similarities and differences between the LVF half-face advantage and the LVF advantage for whole faces. As with pairs of LVF and RVF half-faces, LVF advantages are observed for pairs of whole faces viewed in the periphery (Van der Haegen \& Brysbaert, 2018), which may be related to inter-hemifield competition for faceprocessing resources induced by whole faces viewed simultaneously in opposite hemifields (Gentile \& Jansma, 2012). We also note that the LVF advantage occurs for single whole faces viewed in the periphery (Dundas et al., 2013; Hilliard, 1973; Rizzolatti et al., 1971), in addition to face pairs viewed simultaneously in the LVF and RVF, which highlights an obvious and possibly important difference between the LVF advantage for whole peripherally viewed faces and centrally viewed faces. We conclude that RH superiority alone is not sufficient to explain the LVF advantage in face recognition, and that an additional condition, the prioritization of an upright LVF halfface over a simultaneously viewed upright half-face in the RVF, is necessary to account for the LVF half-face bias.

\section{References}

Bartlett, J. C., Searcy, J. H., \& Abdi, H. (2003). What are the routes to face recognition? In M. A. Peterson \& G. Rhodes (Eds.), Advances in visual cognition. Perception of faces, objects, and scenes: Analytic and holistic processes (pp. 21-47). New York: Oxford University Press.

Barton, J. J. S., Keenan, J. P., \& Bass, T. (2001). Discrimination of spatial relations and features in faces: Effects of inversion and viewing duration. British Journal of Psychology, 92(3), 527-549. https:// doi.org/10.1348/000712601162329

Beaumont, J. G. (1983). Methods for Studying Cerebral Hemispheric Function. In Functions of the Right Cerebral Hemisphere (pp. 113-146). Elsevier. https://doi.org/10.1016/B978-0-12-773250-3. 50009-7

Boremanse, A., Norcia, A. M., \& Rossion, B. (2013). An objective signature for visual binding of face parts in the human brain. Journal of Vision, 13(11), 6-6. https://doi.org/10.1167/13.11.6

Boremanse, A., Norcia, A. M., \& Rossion, B. (2014). Dissociation of part-based and integrated neural responses to faces by means of electroencephalographic frequency tagging. European Journal of Neuroscience, 40(6), 2987-2997. https://doi.org/10.1111/ejn.12663

Bourne, V. J. (2006). The divided visual field paradigm: Methodological considerations. Laterality, 11(4), 373-393. https://doi.org/10.1080/ 13576500600633982

Bourne, V. J. (2008). Chimeric faces, visual field bias, and reaction time bias: Have we been missing a trick? Laterality: Asymmetries of Body, Brain and Cognition, 13(1), 92-103. https://doi.org/10. 1080/13576500701754315

Bourne, V. J. (2011). Examining the effects of inversion on lateralisation for processing facial emotion. Cortex, 47(6), 690-695. https://doi. org/10.1016/j.cortex.2010.04.003

Brady, N., Campbell, M., \& Flaherty, M. (2005). Perceptual asymmetries are preserved in memory for highly familiar faces of self and friend. Brain and Cognition, 58(3), 334-342. https://doi.org/10.1016/j. bandc.2005.01.001

Brainard, D. H. (1997). The Psychophysics Toolbox. Spatial Vision, 10(4), 433-436. https://doi.org/10.1163/156856897X00357

Bukowski, H., Dricot, L., Hanseeuw, B., \& Rossion, B. (2013). Cerebral lateralization of face-sensitive areas in left-handers: Only the FFA does not get it right. Cortex, 49(9), 2583-2589. https://doi.org/10. 1016/j.cortex.2013.05.002

Burt, D. M., \& Perrett, D. I. (1997). Perceptual asymmetries in judgements of facial attractiveness, age, gender, speech and expression. Neuropsychologia, 35(5), 685-693. https://doi.org/10.1016/S00283932(96)00111-X

Butler, S. H., \& Harvey, M. (2005). Does inversion abolish the left chimeric face processing advantage? Neuroreport, 16(18), 1991-1993. https://doi.org/10.1097/00001756-200512190-00004

Cattaneo, Z., Renzi, C., Bona, S., Merabet, L. B., Carbon, C.-C. C., \& Vecchi, T. (2014). Hemispheric asymmetry in discriminating faces differing for featural or configural (second-order relations) aspects. Psychonomic Bulletin and Review, 21(2), 363-369. https://doi.org/ 10.3758/s13423-013-0484-2 
Cheung, O. S., Richler, J. J., Palmeri, T. J., \& Gauthier, I. (2008). Revisiting the Role of Spatial Frequencies in the Holistic Processing of Faces. Journal of Experimental Psychology: Human Perception and Performance, 34(6), 1327-1336. https://doi.org/10. 1037/a0011752

Chua, K. W., \& Gauthier, I. (2016). Category-specific learned attentional bias to object parts. Attention, Perception, \& Psychophysics, 78(1), 44-51. https://doi.org/10.3758/s13414-015-1040-0

Chua, K. W., Richler, J. J., \& Gauthier, I. (2014). Becoming a lunari or taiyo expert: Learned attention to parts drives holistic processing of faces. Journal of Experimental Psychology: Human Perception and Performance, 40(3), 1174-1182. https://doi.org/10.1037/a0035895

Chua, K. W., Richler, J. J., \& Gauthier, I. (2015). Holistic processing from learned attention to parts. Journal of Experimental Psychology: General, 144(4), 723-729. https://doi.org/10.1037/xge0000063

Cohen, J. (1988). Statistical power for the social sciences. Hillsdale, NJ: Laurence Erlbaum and Associates.

Collishaw, S. M., \& Hole, G. J. (2000). Featural and Configurational Processes in the Recognition of Faces of Different Familiarity. Perception, 29(8), 893-909. https://doi.org/10.1068/p2949

Coolican, J., Eskes, G. A., McMullen, P. A., \& Lecky, E. (2008). Perceptual biases in processing facial identity and emotion. Brain and Cognition, 66(2), 176-187. https://doi.org/10.1016/j.bandc. 2007.07.001

Diamond, R., \& Carey, S. (1986). Why faces are and are not special: An effect of expertise. Journal of Experimental Psychology: General, 115(2), 107-117. https://doi.org/10.1037//0096-3445.115.2.107

Dundas, E. M., Plaut, D. C., \& Behrmann, M. (2013). The joint development of hemispheric lateralization for words and faces. Journal of Experimental Psychology. General, 142(2), 348-358. https://doi. org/10.1037/a0029503

Dundas, E. M., Plaut, D. C., \& Behrmann, M. (2015). Variable lefthemisphere language and orthographic lateralization reduces righthemisphere face lateralization. Journal of Cognitive Neuroscience, 27(5), 913-925. https://doi.org/10.1162/jocn_a_00757

Farah, M. J., Tanaka, J. W., \& Drain, H. M. (1995). What causes the face inversion effect? Journal of Experimental Psychology: Human Perception and Performance, 21(3), 628-634. https://doi.org/10. 1037/0096-1523.21.3.628

Faul, F., Erdfelder, E., Buchner, A., \& Lang, A. G. (2009). Statistical power analyses using $\mathrm{G} *$ Power 3.1: Tests for correlation and regression analyses. Behavior Research Methods, 41(4), 1149-1160. https://doi.org/10.3758/BRM.41.4.1149

Freire, A., Lee, K., \& Symons, L. A. (2000). The face-inversion effect as a deficit in the encoding of configurai information: Direct evidence. Perception, 29(2), 159-170. https://doi.org/10.1068/p3012

Gauthier, I., Tarr, M. J., Anderson, A. W., Skudlarski, P., \& Gore, J. C. (1999). Activation of the middle fusiform "face area" increases with expertise in recognizing novel objects. Nature Neuroscience, 2(6), 568-573. https://doi.org/10.1038/9224

Gentile, F., \& Jansma, B. M. (2010). Neural competition through visual similarity in face selection. Brain Research, 1351, 172-184. https:// doi.org/10.1016/j.brainres.2010.06.050

Gentile, F., \& Jansma, B. M. (2012). Temporal dynamics of face selection mechanism in the context of similar and dissimilar faces: ERP evidence for biased competition within the ventral occipito-temporal cortex using ICA. NeuroImage, 59(1), 682-694. https://doi.org/10. 1016/j.neuroimage.2011.07.018

Gilbert, C., \& Bakan, P. (1973). Visual asymmetry in perception of faces. Neuropsychologia, 11(3), 355-362. https://doi.org/10.1016/00283932(73)90049-3

Goffaux, V., \& Rossion, B. (2006). Faces are "spatial"-holistic face perception is supported by low spatial frequencies. Journal of Experimental Psychology: Human Perception and Performance, 32(4), 1023-1039. https://doi.org/10.1037/0096-1523.32.4.1023
Goffaux, V., \& Rossion, B. (2007). Face Inversion Disproportionately Impairs the Perception of Vertical but not Horizontal Relations Between Features. Journal of Experimental Psychology: Human Perception and Performance, 33(4), 995-1002. https://doi.org/10. 1037/0096-1523.33.4.995

Hasson, U., Levy, I., Behrmann, M., Hendler, T., \& Malach, R. (2002). Eccentricity Bias as an Organizing Principle for Human High-Order Object Areas. Neuron, 34(3), 479-490. https://doi.org/10.1016/ S0896-6273(02)00662-1

Heller, W., \& Levy, J. (1981). Perception and expression of emotion in right-handers and left-handers. Neuropsychologia, 19(2), 263-272. https://doi.org/10.1016/0028-3932(81)90110-X

Hellige, J. B., Corwin, W. H., \& Jonsson, J. E. (1984). Effects of perceptual quality on the processing of human faces presented to the left and right cerebral hemispheres. Journal of Experimental Psychology: Human Perception and Performance, 10(1), 90-107. https://doi.org/10.1037/0096-1523.10.1.90

Hellige, J. B., Jonsson, J. E., \& Michimata, C. (1988). Processing from LVF, RVF and BILATERAL presentations: Examinations of metacontrol and interhemispheric interaction. Brain and Cognition, 7(1), 39-53. https://doi.org/10.1016/0278-2626(88) 90020-6

Hemond, C. C., Kanwisher, N. G., \& Op de Beeck, H. P. (2007). A Preference for Contralateral Stimuli in Human Object- and FaceSelective Cortex. PLoS ONE, 2(6), e574. https://doi.org/10.1371/ journal.pone. 0000574

Hillger, L. A., \& Koenig, O. (1991). Separable mechanisms in face processing: Evidence from hemispheric specialization. Journal of Cognitive Neuroscience, 3(1), 42-58. https://doi.org/10.1162/jocn. 1991.3.1.42

Hilliard, R. D. (1973). Hemispheric Laterality Effects on a Facial Recognition Task in Normal Subjects. Cortex, 9(3), 246-258. https://doi.org/10.1016/S0010-9452(73)80002-4

Hole, G. J. (1994). Configurational factors in the perception of unfamiliar faces. Perception, 23(1), 65-74. https://doi.org/10.1068/p230065

Hsiao, J. H. W., \& Cottrell, G. (2008). Two Fixations Suffice in Face Recognition. Psychological Science, 19(10), 998-1006. https://doi. org/10.1111/j.1467-9280.2008.02191.x

Hsiao, J. H. W., \& Liu, T. T. (2012). The optimal viewing position in face recognition. Journal of Vision, 12(2), 22-22. https://doi.org/10. $1167 / 12.2 .22$

Hsiao, J. H. W., \& Shillcock, R. (2005). Foveal splitting causes differential processing of Chinese orthography in the male and female brain. Cognitive Brain Research, 25(2), 531-536. https://doi.org/10.1016/ j.cogbrainres.2005.08.005

Hunter, Z. R., Brysbaert, M., \& Knecht, S. (2007). Foveal word reading requires interhemispheric communication. Journal of Cognitive Neuroscience, 19(8), 1373-1387. https://doi.org/10.1162/jocn. 2007.19.8.1373

Jacques, C., \& Rossion, B. (2004). Concurrent processing reveals competition between visual representations of faces. NeuroReport, 15(15), 2417-2421. https://doi.org/10.1097/00001756-20041025000023

James, T. W., Arcurio, L. R., \& Gold, J. M. (2013). Inversion effects in face-selective cortex with combinations of face parts. Journal of Cognitive Neuroscience, 25(3), 455-464. https://doi.org/10.1162/ jocn_a_00312

Kanwisher, $\bar{N}$., McDermott, J., \& Chun, M. M. (1997). The fusiform face area: a module in human extrastriate cortex specialized for face perception. The Journal of Neuroscience : The Official Journal of the Society for Neuroscience, 17(11), 4302-4311. https://doi.org/10. 1098/Rstb.2006.1934

Kay, K. N., Weiner, K. S., \& Grill-Spector, K. (2015). Attention Reduces Spatial Uncertainty in Human Ventral Temporal Cortex. Current Biology, 25(5), 595-600. https://doi.org/10.1016/J.CUB.2014.12. 050 
Keenan, P. A., Whitman, R. D., \& Pepe, J. (1989). Hemispheric asymmetry in the processing of high and low spatial frequencies: A facial recognition task. Brain and Cognition, 11(2), 229-237. https://doi. org/10.1016/0278-2626(89)90019-5

Klein, D., Moscovitch, M., \& Vigna, C. (1976). Attentional mechanisms and perceptual asymmetries in tachistoscopic recognition of words and faces. Neuropsychologia, 14(1), 55-66. https://doi.org/10.1016/ 0028-3932(76)90007-5

Kolb, B., Milner, B., \& Taylor, L. (1983). Perception of faces by patients with localized cortical excisions. Canadian Journal of Psychology, 37(1), 8-18. https://doi.org/10.1037/h0080697

Kovács, P., Knakker, B., Hermann, P., Kovács, G., \& Vidnyánszky, Z. (2017). Face inversion reveals holistic processing of peripheral faces. Cortex, 97, 81-95. https://doi.org/10.1016/j.cortex.2017.09. 020

Lavidor, M., \& Ellis, A. W. (2003). Interhemispheric Integration of Letter Stimuli Presented Foveally or Extra-Foveally. Cortex, 39(1), 69-83. https://doi.org/10.1016/S0010-9452(08)70075-3

Lavidor, M., \& Walsh, V. (2004). The nature of foveal representation. Nature Reviews. Neuroscience, 5(9), 729-735. https://doi.org/10. 1038/nrn1498

Leder, H., \& Bruce, V. (2000). When inverted faces are recognized: The role of configural information in face recognition. Quarterly Journal of Experimental Psychology Section A: Human Experimental Psychology, 53(2), 513-536. https://doi.org/10.1080/713755889

Leder, H., \& Carbon, C.-C. C. (2006). Face-specific configural processing of relational information. British Journal of Psychology, 97(1), 19-29. https://doi.org/10.1348/000712605X54794

Leehey, S., Carey, S., Diamond, R., \& Cahn, A. (1978). Upright and Inverted Faces: The Right Hemisphere Knows the Difference. Cortex, 14(3), 411-419. https://doi.org/10.1016/S0010-9452(78) $80067-7$

Levine, S. C., \& Koch-Weser, M. P. (1982). Right hemisphere superiority in the recognition of famous faces. Brain and Cognition, 1(1), 10 22. https://doi.org/10.1016/0278-2626(82)90003-3

Levine, S. C., \& Levy, J. (1986). Perceptual asymmetry for chimeric faces across the life span. Brain and Cognition, 5(3), 291-306. https://doi. org/10.1016/0278-2626(86)90033-3

Levy, I., Hasson, U., Avidan, G., Hendler, T., \& Malach, R. (2001). Center-periphery organization of human object areas. Nature Neuroscience, 4(5), 533-539. https://doi.org/10.1038/87490

Levy, J., Heller, W., Banich, M. T., \& Burton, L. A. (1983a). Are variations among right-handed individuals in perceptual asymmetries caused by characteristic arousal differences between hemispheres? Journal of Experimental Psychology: Human Perception and Performance, 9(3), 329-359. https://doi.org/10.1037/0096-1523.9. 3.329

Levy, J., Heller, W., Banich, M. T., \& Burton, L. A. (1983b). Asymmetry of perception in free viewing of chimeric faces. Brain and Cognition, 2(4), 404-419. https://doi.org/10.1016/0278-2626(83) 90021-0

Levy, J., Trevarthen, C., \& Sperry, R. W. (1972). Perception of bilateral chimeric figures following hemispheric deconnexion. Brain, 95(1), 61-78. https://doi.org/10.1093/brain/95.1.61

Lindell, A. K., \& Nicholls, M. E. R. (2003). Cortical representation of the fovea: Implications for visual half-field research. Cortex (Vol. 39, pp. 111-117). https://doi.org/10.1016/S0010-9452(08)70079-0

Liu, T. T., Hayward, W. G., Oxner, M., \& Behrmann, M. (2014). Holistic processing for left-right composite faces in Chinese and Caucasian observers. Visual Cognition, 22(8), 1050-1071. https://doi.org/10. 1080/13506285.2014.944613

Luh, K. E. (1998). Effect of inversion on perceptual biases for chimeric faces. Brain and Cognition, 37(1), 105-108. Retrieved from http:// psycnet.apa.org/record/1998-04889-030

Luh, K. E., Rueckert, L. M., \& Levy, J. (1991). Perceptual asymmetries for free viewing of several types of chimeric stimuli. Brain and
Cognition, 16(1), 83-103. https://doi.org/10.1016/0278-2626(91) 90087-O

Mäkelä, P., Näsänen, R., Rovamo, J., \& Melmoth, D. (2001). Identification of facial images in peripheral vision. Vision Research, 41(5), 599-610. https://doi.org/10.1016/S0042-6989(00) 00259-5

Martinez, A., Moses, P., Frank, L., Buxton, R., Wong, E., \& Stiles, J. (1997). Hemispheric asymmetries in global and local processing: evidence from fMRI. Neuroreport, 8(7), 1685-1689. Retrieved from http://www.ncbi.nlm.nih.gov/pubmed/9189915

Marzi, C. A., \& Berlucchi, G. (1977). Right visual field superiority for accuracy of recognition of famous faces in normals. Neuropsychologia, 15(6), 751-756. https://doi.org/10.1016/00283932(77)90005-7

Maurer, D., Le Grand, R., \& Mondloch, C. J. (2002). The many faces of configural processing. Trends in Cognitive Sciences. https://doi.org/ 10.1016/S1364-6613(02)01903-4

Mckone, E., \& Yovel, G. (2009). Why does picture-plane inversion sometimes dissociate perception of features and spacing in faces, and sometimes not? toward a new theory of holistic processing. Psychonomic Bulletin and Review, 16(5), 778-797. https://doi.org/ 10.3758/PBR.16.5.778

Milner, A. D., \& Dunne, J. J. (1977). Lateralised perception of bilateral chimaeric faces by normal subjects. Nature, 268(5616), 175-176. https://doi.org/10.1038/268175a0

Moreno, C. R., Borod, J. C., Welkowitz, J., \& Alpert, M. (1990). Lateralization for the expression and perception of facial emotion as a function of age. Neuropsychologia, 28(2), 199-209. https://doi. org/10.1016/0028-3932(90)90101-S

Oldfield, R. C. C. (1971). The assessment and analysis of handedness: The Edinburgh inventory. Neuropsychologia, 9(1), 97-113. https:// doi.org/10.1016/0028-3932(71)90067-4

Parkin, A. J., \& Williamson, P. (1987). Cerebral Lateralisation at Different Stages of Facial Processing. Cortex, 23(1), 99-110. https://doi.org/10.1016/S0010-9452(87)80022-9

Perrett, D. I., Rolls, E. T., \& Caan, W. (1982). Visual neurones responsive to faces in the monkey temporal cortex. Experimental Brain Research, 47(3). https://doi.org/10.1007/BF00239352

Piepers, D. W., \& Robbins, R. A. (2012). A review and clarification of the terms "holistic," "configural," and "relational" in the face perception literature. Frontiers in Psychology. Frontiers Media SA. https://doi. org/10.3389/fpsyg.2012.00559

Puce, A., Allison, T., Asgari, M., Gore, J. C., \& McCarthy, G. (1996). Differential sensitivity of human visual cortex to faces, letterstrings, and textures: a functional magnetic resonance imaging study. The Journal of Neuroscience: The Official Journal of the Society for Neuroscience, 16(16), 5205-5215. https://doi.org/10.1523/ JNEUROSCI.16-16-05205.1996

Ramon, M., \& Rossion, B. (2012). Hemisphere-dependent holistic processing of familiar faces. Brain and Cognition, 78(1), 7-13. https:// doi.org/10.1016/j.bandc.2011.10.009

Rhodes, G. (1985). Perceptual asymmetries in face recognition. Brain and Cognition, 4(2), 197-218. https://doi.org/10.1016/02782626(85)90070-3

Rhodes, G. (1993). Configural Coding, Expertise, and the Right Hemisphere Advantage for Face Recognition. Brain and Cognition, 22(1), 19-41. https://doi.org/10.1006/brcg.1993.1022

Rhodes, G., Brake, S., \& Atkinson, A. P. (1993). What's lost in inverted faces? Cognition, 47(1), 25-57. https://doi.org/10.1016/00100277(93)90061-Y

Richler, J. J., Palmeri, T. J., \& Gauthier, I. (2012). Meanings, Mechanisms, and Measures of Holistic Processing. Frontiers in Psychology, 3, 553. https://doi.org/10.3389/fpsyg.2012.00553

Rizzolatti, G., \& Buchtel, H. A. (1977). Hemispheric Superiority in Reaction Time to Faces: A Sex Difference. Cortex, 13(3), 300 305. https://doi.org/10.1016/S0010-9452(77)80039-7 
Rizzolatti, G., Umiltà, C., \& Berlucchi, G. (1971). Opposite superiorities of the right and left cerebral hemispheres in discriminative reaction time to physiognomical and alphabetical material. Brain, 94(3), 431-442. https://doi.org/10.1093/brain/94.3.431

Rossion, B., Dricot, L., Devolder, A., Bodart, J.-M. M., Crommelinck, M., De Gelder, B., ... Zoontjes, R. (2000). Hemispheric Asymmetries for Whole-Based and Part-Based Face Processing in the Human Fusiform Gyrus. Journal of Cognitive Neuroscience, 12(5), 793-802. https://doi.org/10.1162/089892900562606

Sadr, J., \& Krowicki, L. (2019). Face Perception Loves a Challenge: Less Information Sparks More Attraction. Vision Research. https://doi. org/10.1016/j.visres.2019.01.009

Sayres, R., \& Grill-Spector, K. (2008). Relating retinotopic and objectselective responses in human lateral occipital cortex. Journal of Neurophysiology, 100(1), 249-267. https://doi.org/10.1152/jn. 01383.2007

Schiltz, C., \& Rossion, B. (2006). Faces are represented holistically in the human occipito-temporal cortex. NeuroImage, 32(3), 1385-1394. https://doi.org/10.1016/j.neuroimage.2006.05.037

Schwartz, M., \& Smith, M. L. (1980). Visual asymmetries with chimeric faces. Neuropsychologia, 18(1), 103-106. https://doi.org/10.1016/ 0028-3932(80)90091-3

Searcy, J. H., \& Bartlett, J. C. (1996). Inversion and processing of component and spatial-relational information in faces. Journal of Experimental Psychology: Human Perception and Performance, 22(4), 904-915. https://doi.org/10.1037/0096-1523.22.4.904

Sergent, J. (1982a). About face: Left-hemisphere involvement in processing physiognomies. Journal of Experimental Psychology: Human Perception and Performance, 8(1), 1-14. https://doi.org/10.1037/ 0096-1523.8.1.1

Sergent, J. (1982b). The cerebral balance of power: Confrontation or cooperation? Journal of Experimental Psychology: Human Perception and Performance, 8(2), 253-272. https://doi.org/10. 1037/0096-1523.8.2.253

Sergent, J. (1984a). An investigation into component and configural processes underlying face perception. British Journal of Psychology, 75(2), 221-242. https://doi.org/10.1111/j.2044-8295.1984.tb01895. $\mathrm{X}$

Sergent, J. (1984b). Configural processing of faces in the left and the right cerebral hemispheres. Journal of Experimental Psychology: Human Perception and Performance, 10(4), 554-572. https://doi.org/10. 1037/0096-1523.10.4.554

Sergent, J. (1985). Influence of Task and Input Factors on Hemispheric Involvement in Face Processing. Journal of Experimental Psychology: Human Perception and Performance, 11(6), 846861. https://doi.org/10.1037/0096-1523.11.6.846

Sergent, J., \& Bindra, D. (1981). Differential hemispheric processing of faces: Methodological considerations and reinterpretation. Psychological Bulletin, 89(3), 541-554. https://doi.org/10.1037/ 0033-2909.89.3.541
Sergent, J., Ohta, S., \& Macdonald, B. (1992). Functional neuroanatomy of face and object processing: A positron emission tomography study. Brain, 115(1), 15-36. https://doi.org/10.1093/brain/115.1.15

Siman-Tov, T., Mendelsohn, A., Schonberg, T., Avidan, G., Podlipsky, I., Pessoa, L., ... Hendler, T. (2007). Bihemispheric Leftward Bias in a Visuospatial Attention-Related Network. Journal of Neuroscience, 27(42), 11271-11278. https://doi.org/10.1523/JNEUROSCI.059907.2007

Tanaka, J. W., \& Farah, M. J. (1993). Parts and Wholes in Face Recognition. The Quarterly Journal of Experimental Psychology Section A, 46(2), 225-245. https://doi.org/10.1080/ 14640749308401045

Tanaka, J. W., \& Simonyi, D. (2016). The "parts and wholes" of face recognition: A review of the literature. Quarterly Journal of Experimental Psychology, 69(10), 1876-1889. https://doi.org/10. 1080/17470218.2016.1146780

Van Belle, G., De Graef, P., Verfaillie, K., Rossion, B., \& Lefevre, P. (2010). Face inversion impairs holistic perception: Evidence from gaze-contingent stimulation. Journal of Vision, 10(5), 10-10. https:// doi.org/10.1167/10.5.10

Van der Haegen, L., \& Brysbaert, M. (2018). The relationship between behavioral language laterality, face laterality and language performance in left-handers. PLoS ONE, 13(12), e0208696. https://doi. org/10.1371/journal.pone.0208696

Van Kleeck, M. H. (1989). Hemispheric differences in global versus local processing of hierarchical visual stimuli by normal subjects: New data and a meta-analysis of previous studies. Neuropsychologia, 27(9), 1165-1178. https://doi.org/10.1016/0028-3932(89)90099-7

Wolff, W. (1933). The experimental study of forms of expression. Journal of Personality, 2(2), 168-176. https://doi.org/10.1111/j.1467-6494. 1933.tb02092.x

Yovel, G., Levy, J., Grabowecky, M., \& Paller, K. A. (2003). Neural correlates of the left-visual-field superiority in face perception appear at multiple stages of face processing. Journal of Cognitive Neuroscience, 15(3), 462-474. https://doi.org/10.1162/ 089892903321593162

Yovel, G., Paller, K. A., \& Levy, J. (2005). A whole face is more than the sum of its halves: Interactive processing in face perception. Visual Cognition, 12(2), 337-352. https://doi.org/10.1080/ 13506280444000210

Yovel, G., Tambini, A., \& Brandman, T. (2008). The asymmetry of the fusiform face area is a stable individual characteristic that underlies the left-visual-field superiority for faces. Neuropsychologia, 46(13), 3061-3068. https://doi.org/10.1016/j.neuropsychologia.2008.06. 017

Publisher's note Springer Nature remains neutral with regard to jurisdictional claims in published maps and institutional affiliations. 